\title{
Milestone For E-Navigation: A Concept for Navigational Safety Platform by Means of AISITS
}

\author{
Ketut Buda Artana, AAB Dinariyana, I Made Ariana, Dhimas Widhi Handani, Fadilla \\ Indrayuni Prastyasari and Emmy Pratiwi \\ Center of Excellence for Maritime Safety and Marine Installation \\ Sepuluh Nopember Institute of Technology (ITS) \\ Jl. Teknik Kimia, Keputih, Kec. Sukolilo, Surabaya \\ e-mail: ketutbuda@its.ac.id; ketutbuda@gmail.com
}

\begin{abstract}
The implementation of Automatic Identification System (AIS) was based on IMO Resolution MSC.74 (69) Annex III. This has changed the pattern of communication between ships as well as the pattern of communication of ships to the shore. At the same time, this has also encouraged a variety of new research and innovations, which are mainly due to the extremely valuable data transmitted by AIS. AIS's static and dynamic data when combined with various other data such as environmental data, geographical data, ship databases, territorial data will provide opportunities for the emergence of various IT-based applications that can be utilized not only to ensure the safety of ships, but also can be used for environmental protection and guarantee safety of offshore facilities. Various research and innovations have been developed by various educational and research institutions, including ITS in the context of utilizing AIS data as a basis for producing applications in the platform to support e-navigation with the main objectives are to increase the safety of ships at sea and environmental protection. Several applications developed by ITS have also been utilized by the oil and gas industry. This paper presents the implementation of AIS in Indonesia and explain the effort of adopting AISITS as the platform for enavigation to ensure the safety of navigation in TSS Sunda Strait and Lombok Strait.
\end{abstract}

Keywords: AISITS, E-Navigation, TSS, Safety Operation of Ship, Environmental Protection

\section{Introduction}

This paper is presented at the invitation of Makassar Maritime Polytechnic in the 4th International Conference on Maritime Education and Training ( $4{ }^{\mathrm{TH}}$ ICMET) with the theme of Maritime Education and Training Roles in Supporting Sunda Strait and Lombok Strait as a Traffic Separation Scheme (TSS).

Given the important role of the two straits, the support for an integrated navigation system will make it easier for the Indonesian government to monitor and empower TSS in the two straits. AISITS as one of ITS Surabaya's innovation products is an Automatic Identification System (AIS) based platform initiation which is expected to be an alternative e-navigation platform in Indonesia. In the long term, the platform will be integrated with the use of radar, satellite and other data sources that can provide real-time services to ensure the safety of ship operations and the environment. Several applications such as

This paper is presented in The $4^{\text {th }}$ International Conference on Maritime Education and Training October $8^{\text {th }}, 2020$, Makassar, Indonesia 
early warning systems for offshore platform and subsea pipeline safety have been developed in the AISITS platform. Some of the other applications that are being developed are monitoring the Energy Efficiency Operational Indicator (EEOI) of ships [1], ship services at ports, determining ship risk indexes, monitoring fuel and lubricating oil consumption [1], ship services at ports. AISITS is a platform that is expected to support the implementation of e-navigation in Indonesia.

\section{Research Method}

This paper presents the brief description about the application of AISITS to support the navigational safety in Sunda Strait and Lombok. Firstly, ship collision risk assessment that has been carried out by utilizing AIS data in the designed TSS Sunda strait and Lombok is provided. Then, several challenges in providing e-navigation to support the designation of the Lombok Strait and the Sunda Strait as TSS will be discussed. Lastly, how AISITS can be implemented as a platform for E-Navigation and respond to these challenges is presented.

\section{Results and Analysis}

\subsection{Traffic Separation Scheme (TSS) of Sunda Strait and Lombok Strait}

Traffic separation scheme (TSS) is an approach in managing maritime traffic route - system governed by the International Maritime Organization or IMO. The traffic-lanes (or clearways) indicate the general direction of the ships in that zone. Ships navigating within a TSS all sail in the same direction or they cross the lane in an angle as close to 90 degrees as possible. TSS's are used to regulate the traffic at busy, confined waterways or around capes. Within a TSS there is normally at least one traffic-lane in each maindirection, turning-points, deep-water lanes and separation zones between the main traffic lanes. Most TSS schemes include 'inshore traffic zones' between the traffic-lanes and the coast. The inshore traffic zone is unregulated and is not intended to be used for through traffic but rather for local traffic, fishing and small craft. A ship navigating in a traffic lane should sail in the general direction of that lane. The body of water between two opposite lanes is to be avoided by vessels travelling within the TSS as far as possible except in certain circumstances such as emergencies or for fishing activities. Where needed there are special zones where a lane splits into two channels: one ongoing and the other to the nearby port(s).

Indonesia has granted by IMO to implement traffic separation schemes and other routing measures in the Sunda Strait and Lombok Strait according to $6^{\text {th }}$ NCSR Subcommittee in January 2019, responding to high density of marine traffic in those two straits as shown in Fig 1 and Fig 2. As the results, those new routing measures have been adopted by the IMO 101st session MSC IMO $10^{\text {th }}$ June 2019 and has come into force in the $1 \mathrm{st}$ July 2020. The traffic separation schemes adoption listed in document COLREG.2/ Circ.74 dated $14^{\text {th }}$ June 2019 concerning new traffic separation schemes while routing measures other than traffic separation schemes are listed in SN.1 / Circ.337 on the same date [2], [3]. Based on its adoption, Indonesia has published Notices to Mariners and a new edition of paper charts and ENCs.

New TSS in the Sunda Strait and Lombok Strait is a unique condition due to it is located within the Indonesia Archipelagic Sea Lane (IASL). IASL has been adopted by IMO at MSC.72 (69) on 19th May 1998. Furthermore, UNCLOS 1982 described that an archipelagic States has rights to designate TSS within its ASL and requested all vessels to

This paper is presented in The $4^{\text {th }}$ International Conference on Maritime Education and Training 
respect the adopted TSS therefore where a TSS exists in a narrow channel in such a sea lane (Sunda Strait and Lombok Strait), rules for the use of TSSs apply. The determination of the TSS has taken many aspects into account, including aspects of the customs of ships navigating the Sunda Strait and Lombok Strait.

Through a certain process based on methodology given in Figure 3. Statistical data in the form of marine traffic data, environmental data and bathymetry data were used to model ship traffic operating in each of them. each strait. At the same time, deterministic data in the form of standard and regulation, fishing area, and port data are used as the basis for determining the selection of shipping lane locations. Based on these results, the technical design of shipping lanes and its operational analysis is determined and then verified by performing a simulation in the form of a shipping collision analysis.

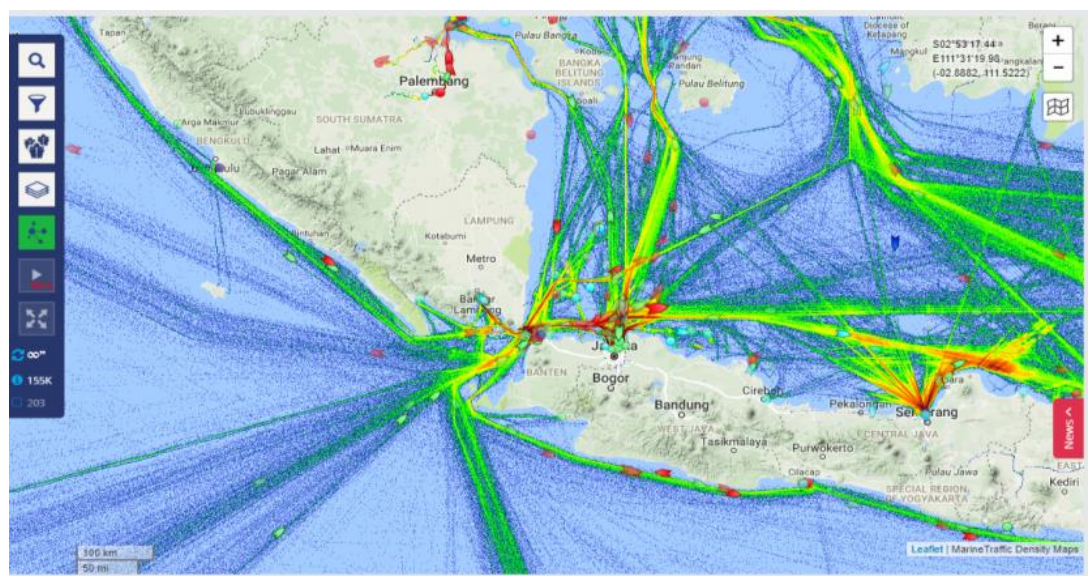

Figure 1. Traffic density at Sunda Strait

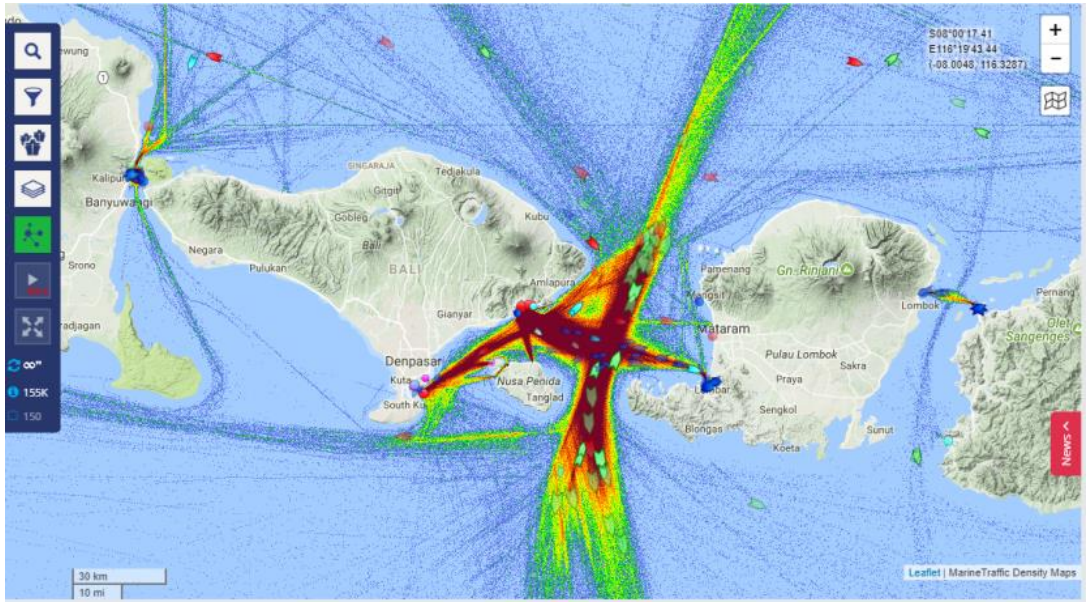

Figure 2. Traffic density at Lombok Strait

This paper is presented in The $4^{\text {th }}$ International Conference on Maritime Education and Training 


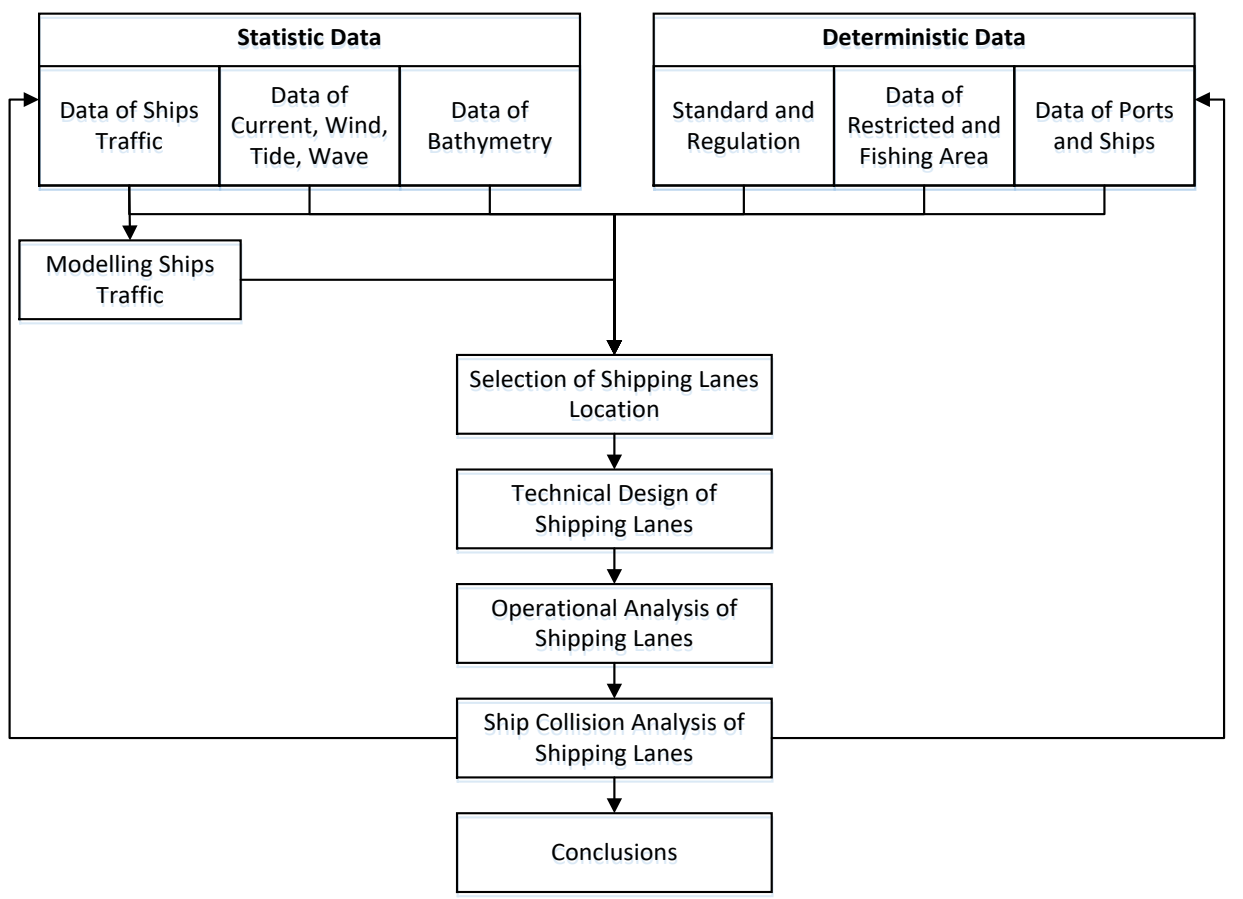

Figure 3. TSS Design Methodology

In ship collision modeling, 3 types of collisions are considered to represent every possible collision that occurs in the Sunda and Lombok Strait [4]. The three types of collisions are head-on, crossing and overtaking. The collision frequency in shipping lanes is calculated manually using the Quantitative Risk Assessment method and using the IWRAP software [5]. The simulation results of the IWRAP software are then verified using several collision model formulas to ensure the compatibility between manual calculations and the results obtained from the software. The TSS design for the Lombok Strait and Sunda Strait was obtained as shown in Figure 4 and Figure 5.

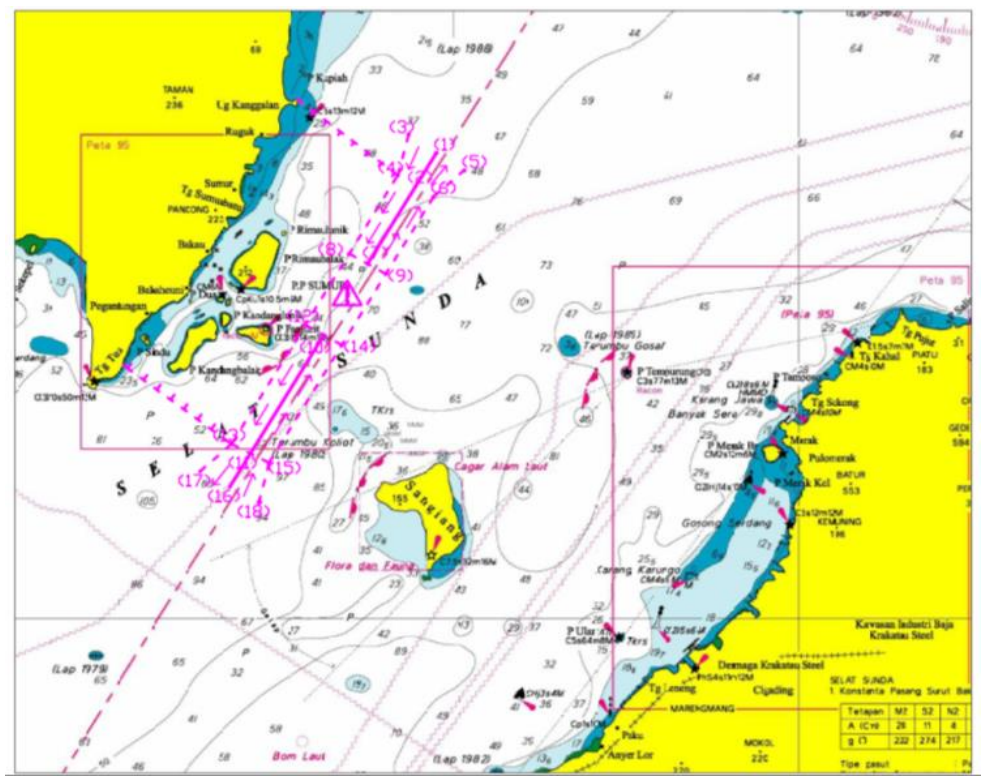

Figure 4. Design of TSS Sunda Strait

This paper is presented in The $4^{\text {th }}$ International Conference on Maritime Education and Training 


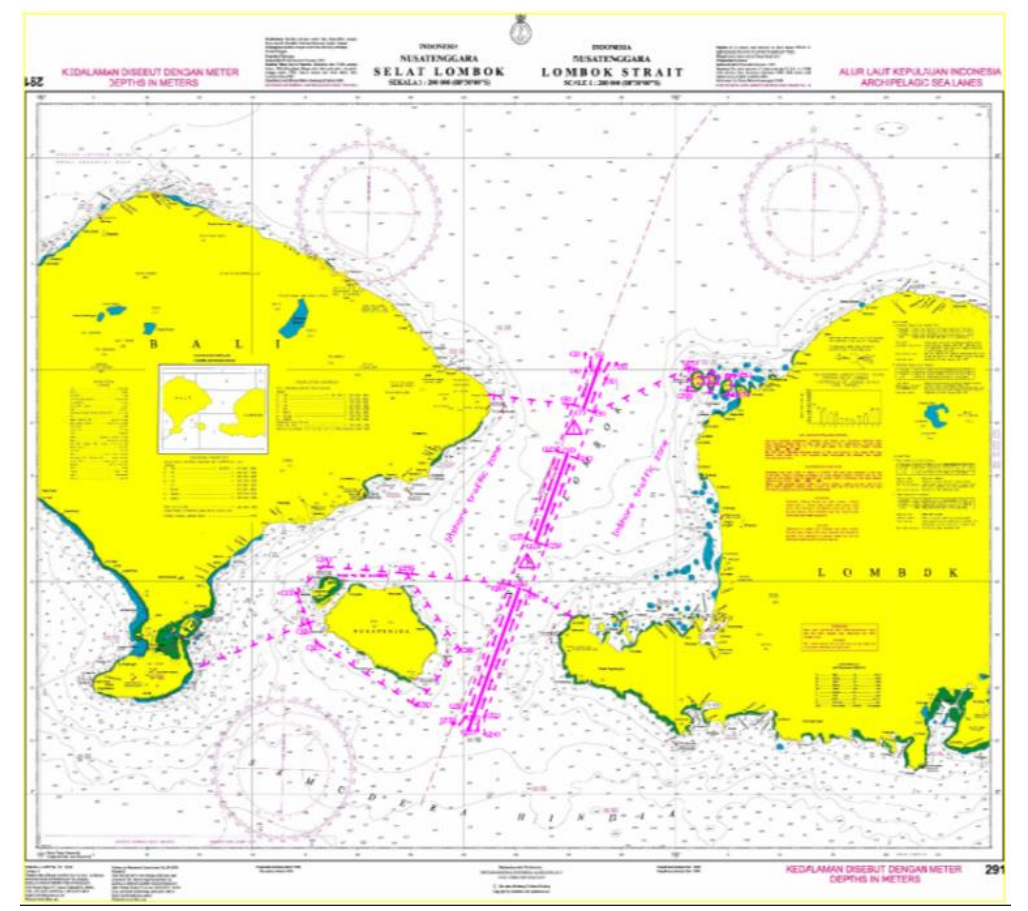

Figure 5. Design of TSS Lombok Strait

\subsection{E-Navigation and the challenges in TSS Implementation}

According to IMO, e-navigation is defined as the harmonized collection, integration, exchange, presentation and analysis of marine information on board and ashore by electronic means to enhance berth to berth navigation and related services for safety and security at sea and protection of the marine environment [6]. The objectives of e-navigation implementation are to improve, harmonize and user-friendly bridge design, means for standardized and automated reporting, to improve reliability, resilience and integrity of bridge equipment and navigation information, to Integrate available information in graphical displays received via communication equipment and to improve Communication of VTS.

In an effort to support the designation of the Lombok Strait and the Sunda Strait as TSS, the Indonesian government has a challenge in providing an electronic-based navigation system that enables monitoring of ship safety and the environment to be carried out in those two straits effectively and reliably.

Several challenges arise in the framework of implementing e-navigation not only for the 2 straits discussed in this paper, but also for the implementation of e-navigation in all sea territory in Indonesia. These challenges include standardization of communication and information equipment on board, standardization of communication and information equipment on the ground, standardization of data, reporting and presentation of information, supporting infrastructure especially ICT, development of information and communication technology, ICT-based applications and support systems and operator skills and abilities as well as accessibility of data and information.

\subsection{AISITS as a Platform for E-Navigation}

AISITS is initially a system to monitor the safety of subsea pipeline and offshore platform. AISITS uses AIS device to get vessels information. AISITS can help the port authority to inspect ships which have the highest hazard value before entering the port.

This paper is presented in The $4^{\text {th }}$ International Conference on Maritime Education and Training 
AISITS has equipped with an alert to warn the port authority. AISITS has 3 main features e.g. Pipeline Early Warning System (PEWS), Ship Inspection, and Ship Movement Recording [7].

Currently, the AISITS is designed as a platform for several under development applications such as application for monitoring the Energy Efficiency Operational Indicator (EEOI) of ships, ship services at ports, determining ship risk indexes, monitoring fuel and lubricants usage, ship services at ports.

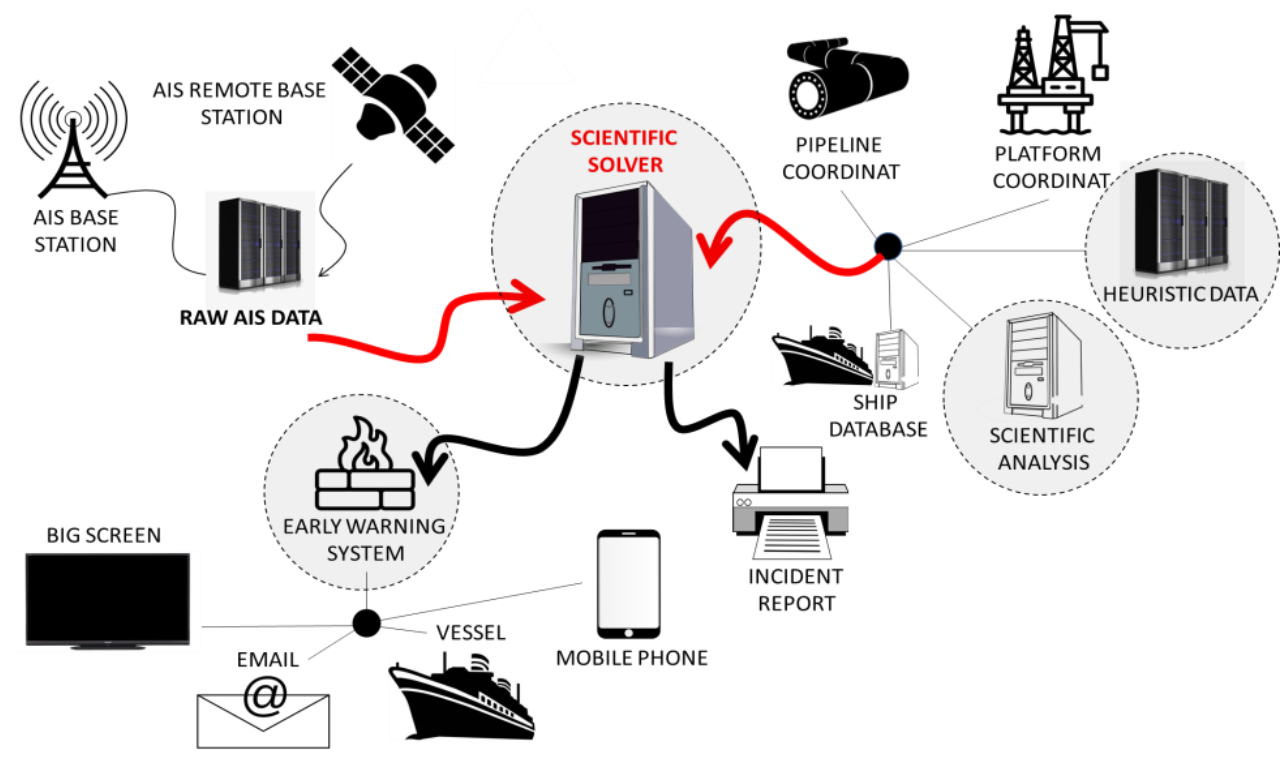

Figure 6. AISITS Platform

Based on ITU (International Telecommunication Union) standard, AIS has 27 message types and each of them has different specifications and utilities. AISITS uses some messages from AIS data to develop the system. These messages are decoded by AISITS and stored in the database. The stored data can be viewed anytime on the website or mobile phone and can show the movement of vessels. There are several data that have been used to determine whether the ships are operated close to the marine facilities e.g., navigation status, heading/course of vessel, velocity of ship and last time ship to sends a data.

Remote AIS Integration is designed so as to enable AISITS control many AIS base stations in one control room. It can help port authorities to monitor ships from other locations at once. User can access it via website or mobile phone and can make a decision faster if there are accidents happening at the port. AISITS gets AIS data from many base stations and the data are send continuously like a data stream. The data stream needs a high capacity storage in the system. AISITS uses down sampling method to reduce the capacity required by the data. AISITS can help forensic analyzers deal with accident investigations at the sea such as a collision between ships, a collision between ships and offshore platform, and a ship capsized caused by a bad weather. AIS data can be shared with other people by AISITS which can be used to do research or to claim the insurance by other authorities.

This paper is presented in The $4^{\text {th }}$ International Conference on Maritime Education and Training 


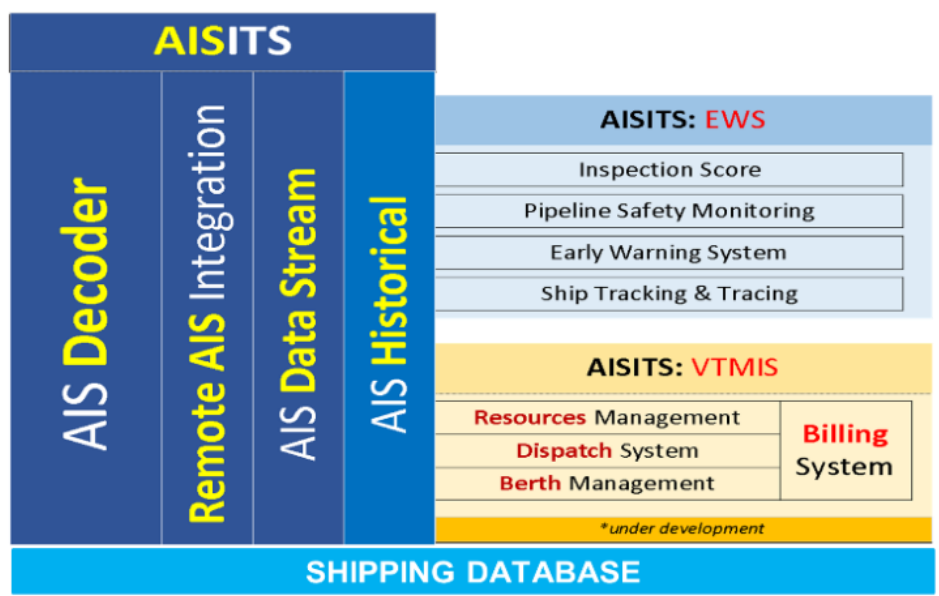

Figure 7. AISITS Hardware and Software structure

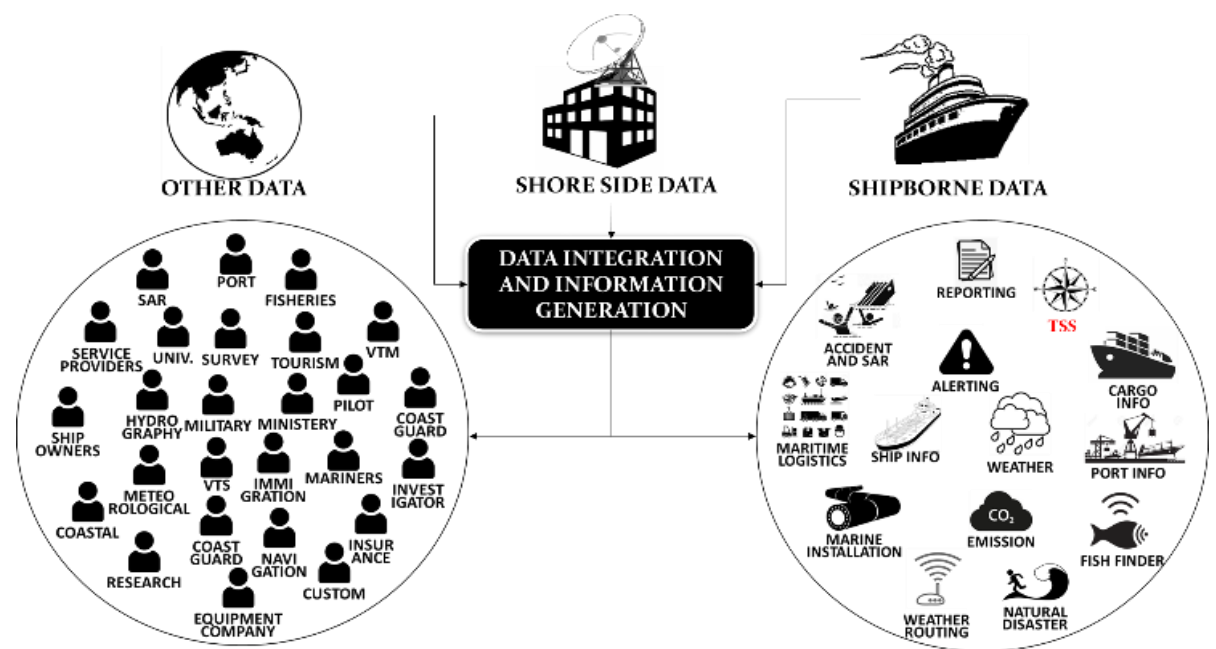

Figure 8. Data integration and information generation

The e-navigation concept that will be developed in the AISITS platform is shown in Figure 3. Data integration and information generation are intended to connect the needs of shore side data and shipborne data. The addition of several other data such as environmental data, shipping databases, marine facilities data, pipeline and platform coordinate data, as well as other data will be integrated into information packaged into reporting systems, TSS arrangements, cargo and ship information, maritime logistics, early warning systems. for marine installation, emission monitoring, fishing services and other relevant information. Further information can be developed as required by other maritime stakeholders. An overview of the concept of application development on the AISITS platform can be seen as in Figure 9. 


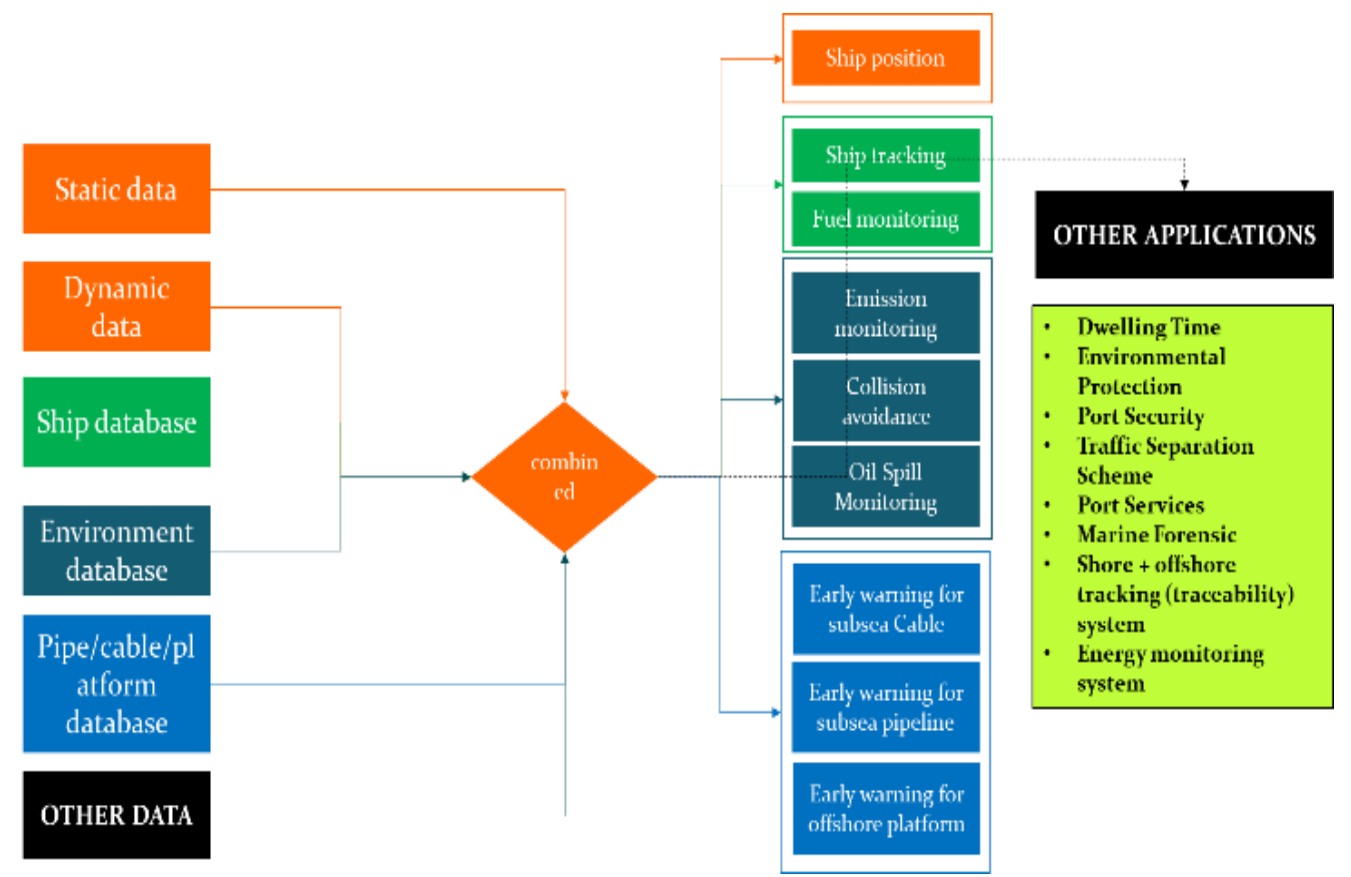

Figure 9. Data integration concept
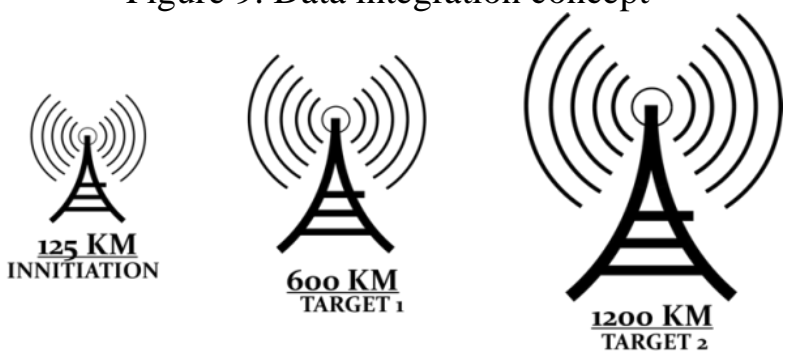

Figure 10. Research on antenna

Currently the center of excellence for maritime safety and marine installation of ITS is intensively conducting research to enable AISITS to have further coverage. The combination of omni antenna and yagi antenna is one of the areas of research being carried out. It is hoped that this research will be able to produce an antenna design and configuration that can reach up to $600 \mathrm{KM}$ in the first stage. If the antenna research is successful, it is hoped that it will be able to reduce the required AISITS investment.

\subsection{AISITS Consortium and Activities}

In order to support efforts in research and development of AISITS in supporting enavigation in Indonesia, ITS has donated AISITS equipment to 5 universities in Indonesia which will later be part of the AIS research consortium. The donated equipment will be used to obtain marine traffic data and use it in various research and application development. Figure 11 shows some of the grant activities that have been implemented. This consortium is also intended to increase the coverage of AISITS which in the end is expected to provide more information that supports the operational safety of ships at sea especially to ensure the safety in TSS.

This paper is presented in The $4^{\text {th }}$ International Conference on Maritime Education and Training 


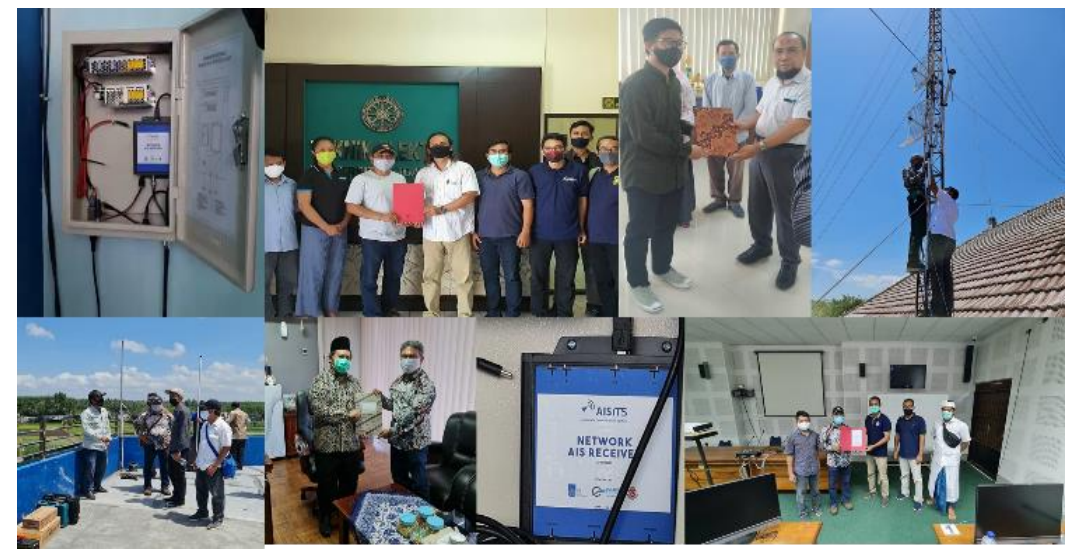

Figure 11. AIS Research Consortium

\section{Conclusion}

TSS has been implemented in two important straits in Indonesia, Sunda Strait and Lombok Strait. In order to provide an easier monitoring of ship traffic in the two straits, an integrated navigation system should be provided by the government. ITS Surabaya has been conducting long research about the utilization of AIS data for several application related to subsea facilities and ship traffic. AISITS as one of ITS Surabaya's innovation products is an AIS based platform initiation which has highly potential to become an alternative e-navigation platform in Indonesia. In addition, research and development of AISITS is still being carried out by expanding the coverage of AISITS and conducting a research consortium with several universities in Indonesia.

\section{References}

[1] A. T. A. Wijaya, I. M. Ariana, D. W. Handani, and H. N. Abdillah, "Fuel Oil Consumption Monitoring and Predicting Gas Emission Based on Ship Performance using Automatic Identification System (AISITS) Data," IOP Conf. Ser.: Earth Environ. Sci., vol. 557, p. 012017, Sep. 2020, doi: 10.1088/1755-1315/557/1/012017.

[2] International Maritime Organization (IMO), COLREG.2/Circ.74 NEW TRAFFIC SEPARATION SCHEMES. 2019.

[3] International Maritime Organization (IMO), SN.1/Circ.337 Routeing Measures Other Than Traffic Separation Schemes. 2019.

[4] N. D. Wuryaningrum, D. W. Handani, F. I. Prastyasari, and A. B. Dinariyana, "Frequency Analysis of Ship Collision and Its Impact on The Fulfillment of Supporting Facilities and Route Changes Due to Implementation of Sunda Strait TSS," IOP Conf. Ser.: Earth Environ. Sci., vol. 557, p. 012042, Sep. 2020, doi: 10.1088/1755-1315/557/1/012042.

[5] P. Friis-Hansen, E. S. Ravn, and P. C. Engberg, "Basic modelling principles for prediction of collision and grounding frequencies," IWRAP Mark II Working Document, pp. 1-59, 2008.

[6] International Maritime Organization (IMO), MSC Circ1595 E-Navigation Strategy Implementation Plan. 2018.

[7] K. B. Artana, T. Pitana, A. A. B. Dinariyana, M. Ariana, D. Kristianto, and E. Pratiwi, "Real Time Monitoring of Subsea Gas Pipelines, Offshore Platforms, and Ship Inspection Scores Using an Automatic Identification System," Journal of Marine Science and Application, 2017.

This paper is presented in The $4^{\text {th }}$ International Conference on Maritime Education and Training 